\title{
Technical Note: Medium-term morphodynamics in an unprotected sandy beach of the Adriatic Sea
}

\section{Postacchini, L. Soldini, C. Lorenzoni, and A. Mancinelli}

Department of Civil and Building Engineering, and Architecture, Università Politecnica delle Marche, 60131 Ancona, Italy

Received: 30 June 2015 - Accepted: 7 July 2015 - Published: 10 August 2015

Correspondence to: M. Postacchini (m.postacchini@univpm.it)

Published by Copernicus Publications on behalf of the European Geosciences Union.

Technical Note: Medium-term morphodynamics in an unprotected beach

M. Postacchini et al.

\section{Title Page}

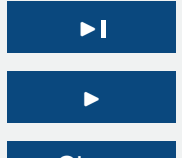

Full Screen / Esc

Printer-friendly Version

Interactive Discussion 


\section{Abstract}

In the recent years attention has been paid to the beach protection by means of soft and hard defenses. Along the Italian coasts of the Adriatic Sea, sandy beaches are the most common landscapes and around $70 \%$ of the Marche-Region coasts (central

5 Adriatic), is protected by defense structures. The longest free-from-obstacle nearshore area in the Region includes the beach of Senigallia, characterized by a multiple barred beach, frequently monitored during the last decades. The bathymetries surveyed in 2006, 2010, 2011, 2012 and 2013 show a good adaptation of the beach to the Deantype equilibrium profile, though a strong short-/medium-term variability of the wave climate has been observed during the monitored periods. This suggests a slight influence of wave forcing on the long-term profiles, which seems to only depend on the sediment size. Further, the medium-term dynamics of the submerged bars and their geometric features have been related to the wave climate collected by a wave buoy located $40 \mathrm{~km}$ off Senigallia during the analyzed temporal windows. An overall inter15 pretation of the complete dynamics, i.e. hydrodynamics (buoy data), sediment characteristics (equilibrium-profile $A$ parameter) and morphodynamics (bathymetric surveys), suggests that the wave climate is fundamental for the morphodynamic changes of the beach in the medium term: waves coming from NNE/ESE are characterized by a larger/smaller steepness and induce seaward/shoreward bar migration, as well as bar smoothing/steepening. Moving southward, the bar dimension increases, while the equilibrium profile suggests a decrease of the sediment size in the submerged beach, this probably due to the presence of both harbor jetty and river mouth North of the investigated area.

\section{Introduction}

25 Some important issues concerning the present society deal with the inundation risk in the coastal areas, the protection of nearshore regions, the use of beaches for tourist
OSD

12, 1711-1728, 2015

Technical Note:

Medium-term

morphodynamics in

an unprotected beach

M. Postacchini et al.

\section{Title Page}

Abstract

Introduction

Conclusions References

Tables

Figures

14

4

Back

Full Screen / Esc

Printer-friendly Version

Interactive Discussion 
and recreational activities. In the last decade, such topics have been of great importance due to short- and long-term predictions associated with the climate change, which is representing a significant threat for what concerns the flooding issue in the present and future years (e.g., see Houghton et al., 2010; Ranasinghe et al., 2013). 5 These changes are associated with both the mean sea-level rise and the more frequent sea storms, also occurring during the summer time. The understanding of the main physical processes driven by such changes is fundamental for (i) the modeling of the nearshore dynamics (e.g., in terms of rapid morphological changes of the beach), (ii) the correct prediction of coastal flooding, and (iii) the proper design of protection 10 solutions (e.g., see Postacchini et al., 2015b).

Several studies (e.g., Benavente et al., 2006; Walton and Dean, 2007) showed that a proper representation of the local bathymetry is fundamental to both correctly predict the seabed changes induced by wave/current forcing and support studies aimed at designing efficient solutions for the coastal protection. It has been demonstrated that

the use of the equilibrium beach proflle (e.g., Dean, 1987, 1991) properly describes the long-term equilibrium of a natural beach, as demonstrated (i) by Walton and Dean (2007), who investigated the main features of the equilibrium beach profile at several cross-shore locations of a nourished beach and after a sea storm, and (ii) by Soldini et al. (2013), who numerically confirmed the feasibility of using an equilibrium beach 20 profile to represent the coastal inundation/flooding of a natural barred beach. The equilibrium profile of a beach represents the balance between erosive and accretive forcing, and is represented by the law:

$h=A y^{n}$,

where $h$ is the water depth and $y$ the distance to shoreline. The features of the equilib25

rium profile depend on a dimensional shape parameter $A$ and on the exponent, which is usually $n=2 / 3$ (Dean, 1991). Dean (1987) proposed an empirical correlation between the parameter $A$, the median grain diameter $d_{50}$ and the sediment fall velocity $w_{\mathrm{f}}$, while

\section{OSD}

12, 1711-1728, 2015

Technical Note:

Medium-term

morphodynamics in

an unprotected beach

M. Postacchini et al.

\section{Title Page}

Abstract

Introduction

Conclusions References

Tables

Figures

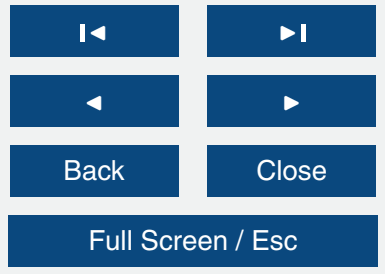

Printer-friendly Version

Interactive Discussion 
Hanson and Kraus (1989) stated that an easier correlation between $A$ and $d_{50}$ could be properly used.

Recently, further models have been developed in order to account for: (i) the beach slope at the swash zone (Komar and McDougal, 1994), (ii) the sediment size variation 5 along the cross-shore profile (Dean and Dalrymple, 2004), (iii) the seasonal changes of the profiles (Inman et al., 1993), (iv) the generation of submerged bars due to wave breaking (Holman et al., 2014). However, the application of such models, which better represent the real equilibrium profile of a beach, is often very difficult, because they require several field data, which are not always available. On the other hand, the simple 10 model (Eq. 1) can be easily used for prediction/design purposes and well represents the long-term natural beach profile (Walton and Dean, 2007; Soldini et al., 2013). The estimate of $A$ can be accomplished by applying, on both natural and theoretical profiles, either a least-square method or an integration of Eq. (1) up to a reference depth.

Submerged subtidal bars are typical of unprotected sandy beaches. They usu15 ally generate on bottom slopes within $0.005-0.03$ and their height ranges between some centimeters to meters (Leont'ev, 2011). In semi-protected and open coasts, twodimensional longshore bars are quite common and have been extensively studied, though the complex mechanisms of generation and migration are not yet completely understood. Generation of submerged bars can be ascribed to three different mech20 anisms, i.e. wave breaking, infragravity waves and self arrangement (Wijnberg and Kroon, 2002). Further, the bar migration mainly depends on the ratio between wave height $H$ and water depth over the bar crest $h_{\mathrm{cr}}$, with values smaller than $\sim 0.3$ or larger than 0.6 promoting, respectively, landward or seaward migration (Houser and Greenwood, 2005). Field observations confirmed a cyclic behavior of multiple bars, mainly characterized by three stages, i.e. initial generation, seaward migration and final degradation (Ruessink and Terwindt, 2000). Conversely, other authors observed a continuous landward motion, until bar-shore welding, even during storm events (Aagaard et al., 2004). The offshore migration is probably promoted by the undertow dominance in the net transport balance (e.g., in the Northern Dutch coast), while the onshore mi-

OSD

12, 1711-1728, 2015

Technical Note:

Medium-term

morphodynamics in

an unprotected beach

M. Postacchini et al.

Title Page

Abstract

Introduction

Conclusions References

Tables

Figures

14

$\rightarrow$ I

4

Back

$\triangleright$

Close

Full Screen / Esc

Printer-friendly Version

Interactive Discussion 
gration is enhanced by storm surges, these both (i) increasing skewness and phase coupling, and (ii) reducing the undertow contribution, which depends on the relative wave height $H / h_{\mathrm{cr}}$ (Aagaard et al., 2004).

The novelty of the paper is represented by the detailed analysis of the seabed evolu5 tion of a natural unprotected beach of the Italian Middle Adriatic, i.e. that of the touristic town of Senigallia (Marche Region, Italy). The available bathymetries, covering the last decade, and the wave climate, enable us to analyze in detail the medium-term morphological evolution of the beach, including the geometry and migration of the submerged bars, as function of the wave forcing. To the authors' knowledge, this is the first study

10 which analyzes the medium-term beach evolution and bar migration occurring in the sandy beaches of the Adriatic Sea.

The manuscript is divided as follows. Section 2 illustrates the available data, while Sect. 3 describes the investigated site. Results are presented in Sect. 4 and discussed in Sect. 5.

\section{Experimental data}

The natural beach South of the harbor of Senigallia was characterized by a number of bathymetric surveys since the $80 \mathrm{~s}$. More recently, due to a specific requirement of the Marche Region, a detailed survey of the nearshore region of Senigallia was undertaken in June 2006, both North and South of the harbor, such areas being respectively 20 characterized by a protected and an unprotected beach. The surveys interested the nearshore region up to a depth of $6 \mathrm{~m}$ and a total length of $4.3 \mathrm{~km}$, most of which $(\sim 3.9 \mathrm{~km})$ in the Southern natural unprotected beach (the final DTM is illustrated in Fig. 1a).

Between 2010 and 2013, after the modification of the harbor entrance, annual bathy25 metric surveys up to a depth of $6 \mathrm{~m}$ were carried out by the municipality of Senigallia on a $2.5 \mathrm{~km}$-long area covering part of the protected and part of the unprotected beaches (example of cross-shore profiles are illustrated in Fig. 1c).

\section{OSD}

12, 1711-1728, 2015

Technical Note:

Medium-term

morphodynamics in an unprotected beach

M. Postacchini et al.

\section{Title Page}

Abstract Introduction

Conclusions References

Tables

Figures

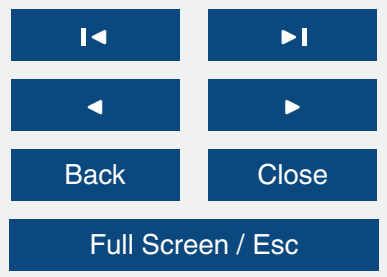

Printer-friendly Version

Interactive Discussion 
The analysis of all surveys enabled us to extract 18 cross-shore profiles which characterize the unprotected beach for about $1 \mathrm{~km}$. This is used for the analysis of the morphological changes induced by the wave climate throughout years, in terms of both bar migration and geometry.

From the analysis of both surveys and satellite data, the submerged bars remain for a stretch of $\sim 12 \mathrm{~km}$. Further, moving southeastward, the sediment size changes, with a transition from sand to gravel occurring $\sim 6 \mathrm{~km}$ South of the harbor (Lorenzoni et al., 1998b). Hence, the initially two-dimensional longshore bars of the investigated area get closer to the shoreline, thus switching to three-dimensional (Fig. 1d). How10 ever, the $\sim 1 \mathrm{~km}$-long area South of the harbor can be taken as representative of the sandy beaches characterizing the Middle Adriatic Sea and will be analyzed in the next sections.

\section{Description of the site}

The studied coast is part of the longest unprotected beach of the Marche Region, 15 which extends from the Senigallia harbor to $\sim 3.5 \mathrm{~km}$ North of the Esino River estuary, hence for a total length of $\sim 12 \mathrm{~km}$ (Fig. 1d). The investigated site is characterized by a swash zone with slope in the range $1: 30-1: 40$, an array of submerged bars in a water depth between 0 and $3 \mathrm{~m}$, and a mild slope of about $1: 200$ for depths larger than $3 \mathrm{~m}$. The emerged beach is characterized by fine $\left(d_{50}=0.125-0.25 \mathrm{~mm}\right)$ ${ }_{20}$ and medium $\left(d_{50}=0.25-0.5 \mathrm{~mm}\right)$ sands, while fine sand was found in the submerged part.

The wave climate in the investigated area was obtained from a waverider of the Italian wave measurement network (RON), located $\sim 23 \mathrm{~nm}$ East-North-East of Senigallia. It worked between March 1999 and March 2006 and between December 2009 and November 2013, the data between 2006 and 2010 surveys thus missing. During the 11 years recordings, the waves mainly came from ESE and NNE (Fig. 1b), the main events hence induced by Bora (coming from NNE) and Levante-Scirocco (from
OSD

12, 1711-1728, 2015

Technical Note:

Medium-term

morphodynamics in

an unprotected beach

M. Postacchini et al.

\section{Title Page}

Abstract

Introduction

Conclusions References

Tables

Figures

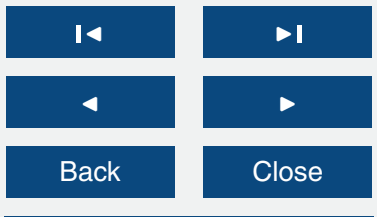

Full Screen / Esc

Printer-friendly Version

Interactive Discussion 
ESE) winds. The wave frequency (empty area) is better distributed throughout the directions, with smooth peaks in correspondence of the main directions ESE and NNE, with respect to the wave energy (full area), characterized by sharper peaks.

The analysis of the beach morphology using the concept of the equilibrium beach 5 profile leads to the estimate of both a fitting depth (e.g., Walton and Dean, 2007) and the shape parameter $A$, which strictly depends on the median grain diameter $d_{50}$. Using either the least-square approach or the continuity of volume, i.e. integration of Eq. (1), the results are similar. From the DTM of Fig. 1a, referring to June 2006, 66 profiles have been extracted. It is important to notice that $A$, and similarly $d_{50}$, decreases moving 10 southward. The largest values occur close to the Senigallia harbor (profile 1 of Fig. 1), i.e. $A \cong 0.069$ and, following Hanson and Kraus (1989), $d_{50} \cong 0.15 \mathrm{~mm}$, while the smallest occur $3.9 \mathrm{~km}$ South of the harbor (profile 66), where $A \cong 0.060$ and $d_{50} \cong 0.13 \mathrm{~mm}$. Such values are in agreement with the fine sand characterizing the submerged beach (Lorenzoni et al., 1998a). A good adaptation to the equilibrium beach profiles, with

\section{Results}

The following sections illustrate the analysis of the seabed variation using the available bathymetric surveys and wave climate. Both migration and geometry of the submerged bars are also discussed.

\section{OSD}

$12,1711-1728,2015$

Technical Note:

Medium-term

morphodynamics in an unprotected beach

M. Postacchini et al.

\section{Title Page}

Abstract Introduction

Conclusions References

Tables

Figures

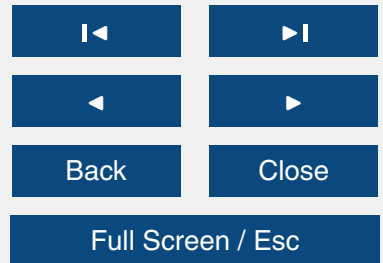

Printer-friendly Version

Interactive Discussion 


\subsection{Bathymetric surveys}

The available bathymetries refer to June 2006, February 2010, February 2011, April 2012 and May 2013. They all have been overlapped using ArcGIS software and the difference in the bed depth have been estimated between each pair of consecutive 5 surveys. Hence, Fig. 2 illustrates the difference between the bed depth measured in 2010 and that measured in 2006 (a), 2011 and 2010 (b), 2012 and 2011 (c), 2013 and 2012 (d). Each case shows seabed variations which are mostly parallel to the coast. Such parallel patterns illustrate the different location of the submerged bars and their migration through years. In each panel, positive/negative values mean that a seabed 10 accretion/erosion occurred during the considered time period. Large positive values indicate either the filling of the bar trough or the new location of the bar crest at the end of the time period (e.g., see the longshore distribution of positive values in Fig. 2a, $\mathrm{b}$, and d, these representing the crest location in, respectively, 2010, 2011, 2013). Further, large negative values may also indicate a bar-crest smoothing and a general beach flattening, as shown in Fig. $2 \mathrm{c}$.

The shoreline is fairly stable and move in the cross-shore direction less than $20 \mathrm{~m}$, with the largest motions occurring within 2006-2010 (advance) and 2011-2012 (retreat). The bar crest locations are overlapped to the color maps of Fig. 2, in order to reconstruct their migration. A shoreward migration of the bars occurred within 2006-2010, 2010-2011 and 2012-2013, while a seaward motion only occurred between 2011 and 2012, when the bars were partially destroyed. After 2012, a partial bar regeneration occurred. The location of the "Rotonda" also affects the bar generation/existence, e.g. in 2010 the offshore bar only exists South of the structure, in 2011 only North.

\subsection{Wave climate}

The wave climate is illustrated at the top right angle of each panel of Fig. 2, except for the period 2006-2010, during which wave data were not available. This shows that the
OSD

12, 1711-1728, 2015

Technical Note:

Medium-term

morphodynamics in

an unprotected beach

M. Postacchini et al.

\section{Title Page}

Abstract

Introduction

Conclusions References

Tables

Figures

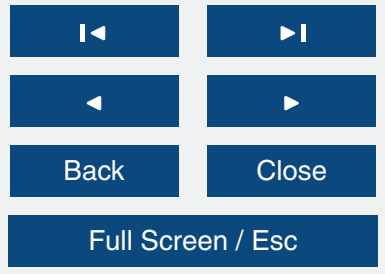

Printer-friendly Version

Interactive Discussion 
most frequent and energetic waves are those coming from either ESE, i.e. forced by Levante-Scirocco winds (Fig. 2b and d), or NNE, i.e. forced by Bora winds (Fig. 2c). While the wave frequency is fairly well distributed throughout the rose, though the NNE and ESE peaks, the wave energy is characterized by sharper peaks in correspondence 5 of of the dominant directions and a reduced distribution elsewhere.

With reference to both frequency and energy flux, a statistic analysis of the main sectors has been undertaken for each time period, i.e. ESE sector (105-135 $)$ for 20102011 and 2012-2013 and NNE sector (15-45 ${ }^{\circ}$ for 2011-2012. During the former time periods, the largest energetic contribution is ascribed to significant wave heights in 10 the range $H_{\mathrm{mo}}=(1-3) \mathrm{m}(2010-2011)$ and $H_{\mathrm{mo}}=(1.5-3.5) \mathrm{m}(2012-2013)$. The most frequent waves falling in such ranges are characterized by mean periods $T_{\mathrm{m}}=(4.5-$ 6) $\mathrm{s}(2010-2011)$ and $T_{\mathrm{m}}=(5-6.5) \mathrm{s}(2012-2013)$. In the same years, peak periods are respectively $T_{\mathrm{p}}=(6.5-8.5) \mathrm{s}$ and $T_{\mathrm{p}}=(7-8.5) \mathrm{s}$. In the NNE period, the largest energetic contribution belongs to a narrower wave-height range, i.e. $H_{\mathrm{m} 0}=(1.5-2.5) \mathrm{m}$, 15 which corresponds to most frequent waves falling within the ranges $T_{m}=(4.5-5.5) \mathrm{s}$ and $T_{\mathrm{p}}=(6-7) \mathrm{s}$.

With the purpose of characterizing each time period with specific wave features, the most energetic direction (ESE/NNE), associated with the most probable wave-height range $H_{\mathrm{m} 0}$, gives the most probable wave-period range $T_{\mathrm{p}}, T_{\mathrm{m}}$. This results in the following mean values, which represent the most probable combinations $\left(H_{\mathrm{m} 0}, T_{\mathrm{m}}\right)$ and $\left(H_{\mathrm{m} 0}, T_{\mathrm{p}}\right)$, related to the most energetic waves.

- 2010-2011: ESE, $H_{\mathrm{m} 0}=1.75 \mathrm{~m}, T_{\mathrm{m}}=5.25 \mathrm{~s}, T_{\mathrm{p}}=7.25 \mathrm{~s}$

- 2011-2012: NNE, $H_{\mathrm{m} 0}=2.25 \mathrm{~m}, T_{\mathrm{m}}=5.25 \mathrm{~s}, T_{\mathrm{p}}=6.75 \mathrm{~s}$

- 2012-2013: ESE, $H_{\mathrm{m} 0}=1.75 \mathrm{~m}, T_{\mathrm{m}}=5.25 \mathrm{~s}, T_{\mathrm{p}}=7.25 \mathrm{~s}$

25 As expected, a larger wave steepness occurs during the NNE period than during the ESE ones.

\section{OSD}

$12,1711-1728,2015$

Technical Note:

Medium-term

morphodynamics in an unprotected beach

M. Postacchini et al.

Title Page

Abstract

Introduction

Conclusions References

Tables

Figures

14

$\rightarrow$ I

4

Back

Full Screen / Esc

Printer-friendly Version

Interactive Discussion 


\subsection{Bar characterization}

The previous data have been used to introduce a detailed analysis of the morphodynamics of the submerged beach, especially the bar geometry and migration. Each of the 18 cross-shore profiles have been characterized by means of: (i) the shoreline po5 sition from a fixed point $\left(s_{\mathrm{sh}}\right)$, (ii) the distance of each bar crest from both fixed point $\left(s_{\mathrm{cr}}\right)$ and shoreline $\left(x_{\mathrm{cr}}=s_{\mathrm{cr}}-s_{\mathrm{sh}}\right)$, and (iii) the bar geometry, i.e. crest $\left(h_{\mathrm{cr}}\right)$ and trough $\left(h_{\mathrm{tr}}\right)$ depths.

Dimensionless parameters are introduced to analyze the bar geometry. In Fig. 3 (top panel) the dimensionless bar height, i.e. the ratio between bar height $\left(H_{\mathrm{bar}}=h_{\mathrm{tr}}-\right.$ $\left.10 h_{\mathrm{cr}}\right)$ and crest depth $h_{\mathrm{cr}}$, is plotted against the dimensionless bar width, i.e. the ratio between bar width $\left(W_{\mathrm{bar}}=2\left(s_{\mathrm{cr}}-s_{\mathrm{tr}}\right)\right)$ and shoreline-crest distance $s_{\mathrm{cr}}$. In general, the bar height seems to increase with the bar width, this occurring for both inner (+), middle $(\square)$ and outer ( $\circ$ ) bars. In particular, a best-fit polynomial curve can be found coupling data referring to outer and middle bars of 2010 (blue dashed line) and 2013 (orange 15 dashed line), in both cases giving determination coefficients $R^{2}>0.5$.

The analysis of the longshore distribution of the bar geometry can be undertaken accounting for the bar cross-shore area $\left(\Omega=H_{\text {bar }} W_{\text {bar }} / 2\right)$, which is made dimensionless using both depth and distance to shore of the bar crest. Figure 3 (bottom panel) illustrates that, in general, all bars increase in dimension quite regularly moving southward.

20 Focusing on years 2010, 2011 and 2013, the middle bars increase regularly between profiles 1 and 10, while South of the "Rotonda" (profiles 11-12), the trend is not clear. The outer bars seem not to be affected by the permeable structure and keep increasing moving southward. In 2006 the middle bar generates and starts increasing from profile 10, while in 2012 the trend is unclear, due to the reduced number of sections at which bars occur. Best-fit curves well reproduce the increasing trend of the outer bars $\left(R^{2}>0.75\right.$ for 2010 and 2013 , dashed lines), more than that of the middle bars $\left(R^{2} \sim 0.5\right)$.

\section{OSD}

12, 1711-1728, 2015

Technical Note:

Medium-term

morphodynamics in

an unprotected beach

M. Postacchini et al.

\section{Title Page}

Abstract

Conclusions

Tables

Figures

14

4

Back

Full Screen / Esc

Printer-friendly Version

Interactive Discussion 


\section{Discussion and conclusions}

The bathymetric surveys of the area South of the Senigallia harbor enabled us to analyze a multiple-bar array typical of the sandy beaches of the Middle Adriatic. Such a part of the basin is subject to sea storms mainly due to NNE (Bora) and ESE (Levante5 Scirocco) winds, which are characterized by significantly different surges.

The seabed-depth variation and the wave climate between contiguous surveys, as well as the bar features (height, width, location) analyzed for each survey, enabled us to couple the beach/bar dynamics with the wave forcing.

In the studied area the tidal excursion $(\sim 40 \mathrm{~cm})$ is small and only subtidal bars ex10 ist. Since the analyzed beach slope ranges between 1:35 0.03 (swash zone) and $1: 200 \sim 0.005$ (offshore area), such bars fall into the group of two-dimensional longshore bars (Wijnberg and Kroon, 2002). Further, the wave energy in such a microtidal environment is quite high.

From the results illustrated in Sect. 4, the bar dynamics in this area may be influenced by either a breakpoint-related or an infragravity wave-related mechanism, while the self-organisational mechanism is negligible, as it can be observed from the partial bar destruction in 2011-2012 and the following re-generation in 2012-2013 (see Figs. 1c and $2 \mathrm{c}$ and d). Such a destructive nature of some storms in the short/medium term suggests that the bar dynamics characterizing the Adriatic sandy beaches are mainly governed by breakpoint mechanisms.

In the analyzed region and during the investigated time periods, the beach experienced many sea storms that enabled us to give an overall interpretation to the bar migration process as a function of the wave climate. During the time periods dominated by ESE forcing, waves are characterized by a reduced steepness $H_{\mathrm{m} 0} / L_{\mathrm{p} 0}=0.213$ (exactly the same in 2010-2011 and 2012-2013), while this is about $1 / 3$ larger during the NNE-forcing-dominated period $\left(H_{\mathrm{m} 0} / L_{\mathrm{p} 0}=0.316\right)$. Such a behavior is also confirmed if we do not account for the most energetic waves (see Sect. 4.2), but directly estimate
OSD

$12,1711-1728,2015$

Technical Note:

Medium-term

morphodynamics in

an unprotected beach

M. Postacchini et al.

\section{Title Page}

Abstract

Introduction

Conclusions References

Tables

Figures

14

4

Back

Full Screen / Esc

Printer-friendly Version

Interactive Discussion 
the most frequent combination $\left(H_{\mathrm{m} 0}, T_{\mathrm{p}}\right)$. Hence, an increase of the bar steepness $H_{\text {bar }} / W_{\text {bar }}$ is associated to a decrease of $H_{\mathrm{mo}} / L_{\mathrm{p} 0}$.

Further, steep NNE waves are associated with reduced storm surges, while gentle ESE waves are characterized by large surges, due to the larger fetch generating in the Adriatic Sea. As an example, two consecutive intense storms occurred in December 2010, the former coming from ESE, the latter from NNE, were characterized by maximum surges of, respectively, 80 and $43 \mathrm{~cm}$, measured at the Ancona harbor (data from Rete Mareografica Nazionale, ISPRA, http://www.mareografico.it). This leads to larger water depths over the crest $h_{\mathrm{cr}}$ during ESE than during NNE waves. Hence, the 10 relative wave height $H / h_{\mathrm{cr}}$ is smaller during ESE waves and larger during NNE forcing, this probably promoting (Houser and Greenwood, 2005) a shoreward migration of the bars in the former case, and a seaward migration in the latter case, which also causes a partial bar destruction. Further, waves coming from ESE are characterized by a significant longshore component, due to the large angle between the coast and 15 the approaching wave fronts. Differently, waves coming from NNE reach the shore with an almost perpendicular incidence, this improving the intense smoothing of the bars.

While the correlation between bar width and height is clear only for some cases, the former increasing with the latter, the cross-shore bar area clearly increases moving southward, especially from the Senigallia harbor to the "Rotonda", this disturbing 20 the middle bar growth. A similar trend has also been found from inspection of the $A$ parameter of the equilibrium profile, which suggests a slight decrease of the sand size moving southward, this being in agreement with the sediment-size distribution observed in 1989 and 1990 by Lorenzoni et al. (1998a). A physical explanation of such a sediment distribution is the presence of the harbor jetty, which induces a complex flow field, i.e. a mix of refraction, diffraction and reflection, that generates a cross sea (e.g., see Postacchini et al., 2014), especially during sea storms coming from ESE (Fig. 1a). Such a dynamics promotes a mobilization of finer sands and their transport far from the jetty.

\section{OSD}

$12,1711-1728,2015$

Technical Note:

Medium-term

morphodynamics in

an unprotected beach

M. Postacchini et al.

\section{Title Page}

Abstract

Introduction

Conclusions References

Tables

Figures

14

4

Back

Full Screen / Esc

Printer-friendly Version

Interactive Discussion 
Finally, the present work illustrates a preliminary analysis of the medium-term dynamics of an unprotected sandy barred beach of the Middle Adriatic Sea. A more detailed analysis can be achieved through use of either data collected by another waverider (e.g., that of Cesenatico, FC, which is $\sim 80 \mathrm{~km}$ North of Senigallia) or a recon5 structed climate (e.g., Mentaschi et al., 2015) to characterize the wave forcing in the period 2006-2010. Further, the dynamics of the nearshore area before, during and after storm events could also be inspected by means of novel devices like: Lagrangian drifters, able at measuring both three-dimensional hydrodynamics and seabed depth (Postacchini et al., 2015a), or video-monitoring of the nearshore area, available since 10 July-August 2015 in the framework of the EsCoSed Project (Brocchini et al., 2015).

\section{References}

Aagaard, T., Davidson-Arnott, R., Greenwood, B., and Nielsen, J.: Sediment supply from shoreface to dunes: linking sediment transport measurements and long-term morphological evolution, Geomorphology, 60, 205-224, 2004. 1714, 1715

15 Benavente, J., Río, L. D., Gracia, F., and del Pozo, J. M.: Coastal flooding hazard related to storms and coastal evolution in Valdelagrana spit (Cadiz Bay Natural Park, SW Spain), Cont. Shelf Res., 26, 1061-1076, 2006. 1713

Brocchini, M., Calantoni, J., Reed, A. H., Postacchini, M., Lorenzoni, C., Russo, A., Mancinelli, A., Corvaro, S., Moriconi, G., and Soldini, L.: Summertime conditions of a muddy estuarine environment: the EsCoSed project contribution, Water Sci. Technol., 71, 14511457, 2015. 1723

Dean, R. G.: Coastal sediment processes: toward engineering solutions, in: Coastal Sediments (1987), ASCE, New York, USA, 1-24, 1987. 1713

Dean, R. G.: Equilibrium beach profiles: characteristics and applications, J. Coastal Res., 7, $25 \quad 53-84,1991.1713$

Dean, R. G. and Dalrymple, R. A.: Coastal Processes with Engineering Applications, Cambridge University Press, Cambridge, UK , 2004. 1714

\section{OSD}

12, 1711-1728, 2015

Technical Note:

Medium-term

morphodynamics in

an unprotected beach

M. Postacchini et al.

Title Page

Abstract

Introduction

Conclusions References

Tables

Figures

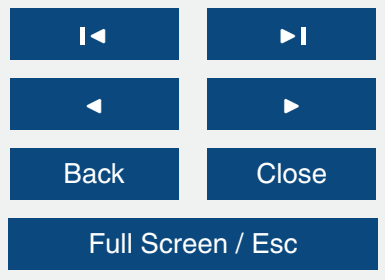

Printer-friendly Version

Interactive Discussion 
Hanson, H. and Kraus, N. C.: GENESIS: Generalized Model for Simulating Shoreline Change, Report 1, Technical Reference, Tech. rep., Coastal Engineering Research Center, Vicksburg, MS, USA, DTIC Document, 1989. 1714, 1717

Holman, R. A., Lalejini, D. M., Edwards, K., and Veeramony, J.: A parametric model for barred equilibrium beach profiles, Coast. Eng., 90, 85-94, 2014. 1714

Houghton, K., Vafeidis, A., Neumann, B., and Proelss, A.: Maritime boundaries in a rising sea, Nat. Geosci., 3, 813-816, 2010. 1713

Houser, C. and Greenwood, B.: Profile response of a lacustrine multiple barred nearshore to a sequence of storm events, Geomorphology, 69, 118-137, 2005. 1714, 1722

10 Inman, D. L., Elwany, M. H. S., and Jenkins, S. A.: Shorerise and bar-berm profiles on ocean beaches, J. Geophys. Res.-Oceans, 98, 18181-18199, 1993. 1714

Komar, P. D. and McDougal, W. G.: The analysis of exponential beach profiles, J. Coastal Res., 10, 59-69, 1994. 1714

Leont'ev, I.: Submarine bars on sandy coasts, Oceanology+, 51, 141-147, 2011. 1714

15 Lorenzoni, C., Mancinelli, A., and Soldini, L.: Caratteristiche sedimentologiche del litorale a Nord di Ancona. Analisi del movimento delle ghiaie (in Italian), in: Atti dell'Istituto di Idraulica dell'Università di Ancona, Università di Ancona, Ancona, p. 54, 1998a. 1717, 1722

Lorenzoni, C., Mancinelli, A., and Soldini, L.: Evoluzione batimetrica del litorale a nord di Ancona. Analisi del trasporto solido trasversale (in Italian), in: Atti dell'Istituto di Idraulica dell'Università di Ancona, Università di Ancona, Ancona, p. 46, 1998b. 1716

Mentaschi, L., Besio, G., Cassola, F., and Mazzino, A.: Performance evaluation of Wavewatch III in the Mediterranean Sea, Ocean Model., 90, 82-94, 2015. 1723

Postacchini, M., Brocchini, M., and Soldini, L.: Vorticity generation due to cross-sea, J. Fluid Mech., 744, 286-309, 2014. 1722

Postacchini, M., Centurioni, L. R., Braasch, L., Brocchini, M., and Vicinanza, D.: Lagrangian Observations of Waves and Currents From the River Drifter, doi:10.1109/JOE.2015.2418171, 2015a. 1723

Postacchini, M., Russo, A., Carniel, S., and Brocchini, M.: Assessing the hydro-morphodynamic response of a beach protected by detached, impermeable, submerged breakwaters: a numerical approach, J. Coastal Res., in press, 2015b. 1713

Ranasinghe, R., Duong, T., Uhlenbrook, S., Roelvink, D., and Stive, M.: Climate-change impact assessment for inlet-interrupted coastlines, Nat. Clim. Chang., 3, 83-87, 2013. 1713
OSD

$12,1711-1728,2015$

Technical Note:

Medium-term

morphodynamics in

an unprotected beach

M. Postacchini et al.

Title Page

Abstract

Introduction

Conclusions References

Tables

Figures

14

4

Back

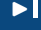

Close

Full Screen / Esc

Printer-friendly Version

Interactive Discussion 
Ruessink, B. and Terwindt, J.: The behaviour of nearshore bars on the time scale of years: a conceptual model, Mar. Geol., 163, 289-302, 2000. 1714

Soldini, L., Antuono, M., and Brocchini, M.: Numerical modeling of the influence of the beach profile on wave run-up, J. Waterw. Port C.-ASCE, 139, 61-71, 2013. 1713, 1714

5 Walton, T. and Dean, R.: Temporal and spatial change in equilibrium beach profiles from the Florida Panhandle, J. Waterw. Port C.-ASCE, 133, 364-376, 2007. 1713, 1714, 1717

Wijnberg, K. M. and Kroon, A.: Barred beaches, Geomorphology, 48, 103-120, 2002. 1714, 1721

\section{OSD}

$12,1711-1728,2015$

Technical Note:

Medium-term

morphodynamics in an unprotected beach

M. Postacchini et al.

Title Page

Abstract

Introduction

Conclusions

References

Tables

Figures

14

4

Back

Full Screen / Esc

Printer-friendly Version

Interactive Discussion 


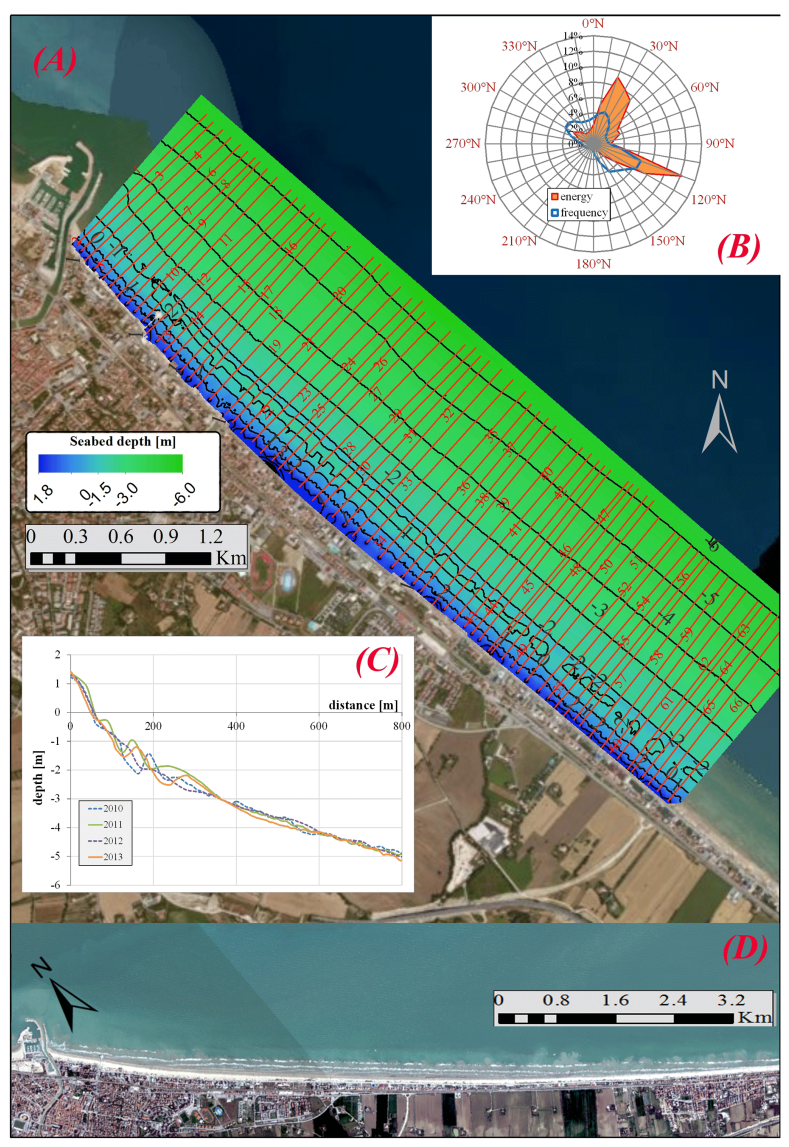

OSD

12, 1711-1728, 2015

Technical Note:

Medium-term

morphodynamics in an unprotected beach

M. Postacchini et al.

Title Page

Abstract

Introduction

Conclusions

References

Tables

Figures

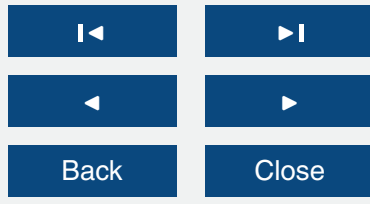

Full Screen / Esc

Printer-friendly Version

Figure 1. Natural beach of Senigallia: (a) bathymetry with isobaths and position of cross-shore profiles referring to June 2006, (b) wave climate referring to the time periods 1999-2006 and 2009-2013, (c) example of cross-shore profile evolution during 2010-2013, (d) satellite view of $\sim 10 \mathrm{~km}$ south of the harbor.

Interactive Discussion 

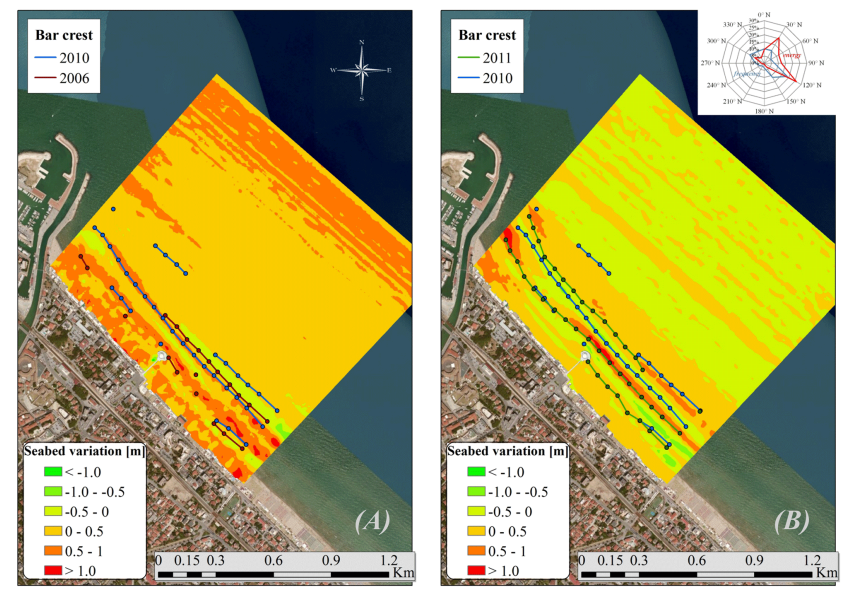

\section{OSD}

12, 1711-1728, 2015

\section{Technical Note: \\ Medium-term}

morphodynamics in an unprotected beach

M. Postacchini et al.

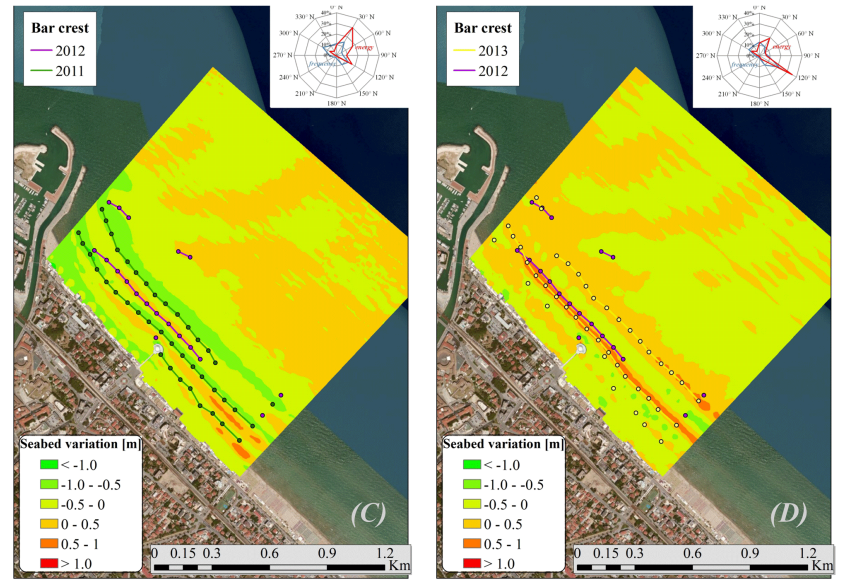

Title Page

Abstract

Introduction

Conclusions

References

Tables

Figures

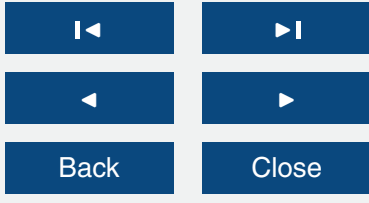

Full Screen / Esc

Printer-friendly Version

Figure 2. Sea bottom variation (color map) and wind rose (top right of each panel) of wave energy and frequency referring to the periods: (a) 2006-2010, (b) 2010-2011, (c) 2011-2012 and (d) 2012-2013.

Interactive Discussion

(c) (1) 


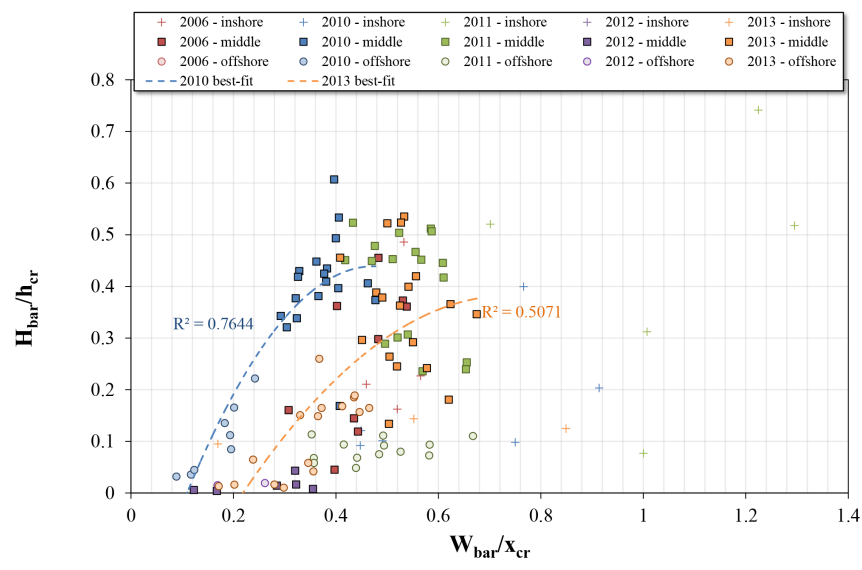

OSD

12, 1711-1728, 2015

Technical Note:

Medium-term

morphodynamics in an unprotected beach

M. Postacchini et al.

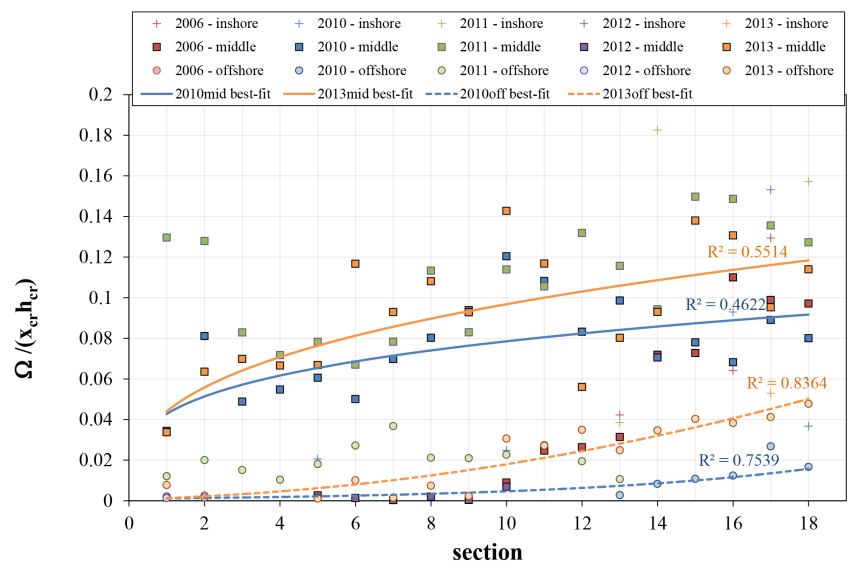

Title Page

Abstract

Introduction

Conclusions

References

Tables

Figures

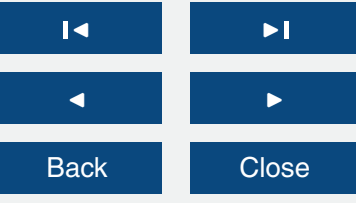

Full Screen / Esc

Printer-friendly Version

Figure 3. Dimensionless features: bar height against bar width (top), longshore distribution of bar cross-shore area (bottom). Dashed and solid lines represent best-fit curves. 